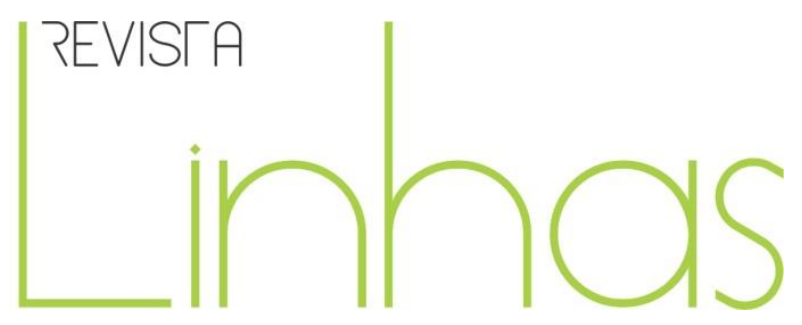

\title{
O corpo produtivo em destaque: preâmbulos sobre educação, trabalho, identidade e mal-estar docente
}

\begin{abstract}
Resumo
Este artigo tem como escopo 'refletir e problematizar sobre as relações entre trabalho, identidade e mal-estar docente no contexto da Educação Básica'. O intuito é pensar essa problemática no âmbito das memórias de desencanto e esperança presentes nas narrativas de professores do passado e do presente da região Oeste de Santa Catarina. A pergunta-problema que norteia o artigo é: em que medida trabalho, mal-estar docente e identidade se amalgamam no cotidiano das práticas pedagógicas? No ponto de vista epistemológico e teórico-metodológico, privilegiamos alguns pressupostos, categorias e leis do materialismo histórico-dialético. No ponto de vista da abordagem metodológica, o artigo faz incursões teórico-empíricas, revisitando os dados brutos do livro Entre esperanças e utopias na Educação Básica: histórias de vida e experiências docentes, organizado pelo Grupo de Estudos do Parfor. Além desses dados, foram feitas algumas entrevistas complementares, com vista a atualizar e precisar os dados acerca do problema de pesquisa. As conclusões provisórias e 'achados' da pesquisa sinalizam para um processo formativo de caráter mais crítico, transformador e revolucionário, para além da lógica do capital. Num sentido propositivo, evidenciamos lutas, tarefas e desafios a serem encarados pelos movimentos sindicais e movimentos sociais, no sentido de, mesmo num quadro adverso de destruição da democracia, continuar as lutas em prol de uma educação pública de qualidade, subvertendo as políticas educacionais atuais que continuam construindo uma identidade alienada dos docentes nas escolas e fora delas.
\end{abstract}

Palavras-chave: Educação. Trabalho. Mal-Estar Docente. Identidade. Narrativas.

\footnotetext{
Alcione Maria Bevilacqua

Universidade Comunitária da Região

de Chapecó - Unochapecó -

Chapecó/SC - Brasil

alcione.qbo@gmail.com

Maurício Roberto da Silva

Universidade Comunitária da Região

de Chapecó - Unochapecó -

Chapecó/SC - Brasil

mauransilva@gmail.com
}

\section{Para citar este artigo:}

BEVILACQUA, Alcione Maria; SILVA, Maurício Roberto da. O corpo produtivo em destaque: preâmbulos sobre educação, trabalho, identidade e mal-estar docente. Revista Linhas. Florianópolis, v. 20, n. 43, p. 290316, maio/ago. 2019. 


\title{
The productive body in highlight: preamble on education, work, identity and teacher unease
}

\begin{abstract}
This article aims to 'reflect and problematize about the relationship between work identity and teacher unease in the context of Basic Education'. The intention is to think about this problem within the context of memories of disenchantment and hope showed on narratives of teachers of the past and the present of the West region of Santa Catarina. The question-problem guiding the article is: in what measure work, teacher's unease and identity are blended in the daily pedagogical practices? From the epistemological and theoretical-methodological point of view, we focus on some assumptions, categories and laws of dialectical historical materialism. Related to methodological approach, the article makes theoretical-empirical incursions, revisiting the raw data of the book Entre esperanças e utopias na Educação Básica: histórias de vida e experiências docentes, organized by Parfor Study Group. In addition to these data, some complementary interviews were made, objectifying to update and clarify the data about the research problem. Provisional conclusions and "findings" of the research, point to a formative process more critical, transformative and revolutionary character beyond the logic of capital. In a propositional way, we demonstrate struggles, tasks and challenges to be faced by union and social movements, at meaning that, even in an adverse scenario of democracy's destruction, the struggles for a quality public education are continuous and subverting the current educational policies that continue to build an alienated identity of teachers inside and outside of schools.
\end{abstract}

Keywords: Education. Work. Teacher Unease. Identity. Narratives. 


\section{Palavras iniciais sobre a construção do problema de pesquisa}

Este artigo tem como escopo 'refletir e problematizar sobre as relações entre trabalho, identidade e mal-estar docente no contexto da Educação Básica'. O intuito é pensar essa problemática no âmbito das memórias de desencanto e esperança presente nas narrativas de professores do passado e do presente da região Oeste de Santa Catarina. A pergunta-problema que norteia o trabalho é: em que medida trabalho, malestar docente e identidade se amalgamam no cotidiano das práticas pedagógicas? Dessa pergunta-síntese, emergem as seguintes questões de pesquisa, que, didaticamente, desdobram-se no artigo: o que é trabalho e suas relações com a educação? O que é trabalho docente, trabalho produtivo e, nessa esteira, o que é corpo produtivo docente? Como os professores o realizam, tendo como mediadores a identidade e a construção do mal-estar docente, desencantos e esperanças? Como os docentes podem se identificar com um sistema que desvaloriza, explora e ignora a importância social e política do trabalho docente?

Postas essas questões, é imprescindível destacar a relevância pessoal, acadêmica, social e política de que se reveste a construção do objeto, cujos dados se originaram, em parte, da dissertação de Mestrado intitulada Trabalho e identidade docente: desencantos e esperanças nas narrativas de professores da região Oeste de Santa Catarina ${ }^{1}$. Quando se fala da relevância do problema de pesquisa em questão (pessoal, acadêmica, política e social), convém destacar que essas diversas dimensões do conhecimento são dialeticamente articuladas, uma vez que repercutem e contribuem com as pesquisas, podendo trazer contribuições e até soluções para situações de relevância pública.

No ponto de vista da abordagem metodológica, o artigo faz incursões teóricoempíricas, revisitando os dados do livro Entre esperanças e utopias na Educação Básica: histórias de vida e experiências docentes, organizado pelo Grupo de Estudos do Programa

\footnotetext{
${ }^{1}$ Dissertação apresentada no Mestrado em Educação da Universidade Comunitária da Região de Chapecó (Unochapecó) em 09/2017. Autora: Alcione Maria Bevilacqua - Orientador: Prof. Dr. Maurício Roberto da Silva.
} 
Nacional de Formação de Professores da Educação Básica (Parfor). ${ }^{2}$ Além desses dados, foram feitas algumas entrevistas complementares, com vistas a atualizar e precisar os dados acerca do problema de pesquisa.

O livro supracitado traz uma coletânea de entrevistas denominada de Diário de Memórias I, realizadas com professores que atualmente estão aposentados e com professores que atuam na Educação Básica e, ao mesmo tempo, são acadêmicos dos cursos do Parfor na Universidade Comunitária da Região de Chapecó (Unochapecó). Durante a leitura, foi possível identificar, através das histórias de vida que compõem as narrativas, achados ricos em informações, que revelam parte da identidade profissional do grupo docente da região Oeste de Santa Catarina.

As narrativas coletadas no Diário de Memórias I, contidas no livro Entre esperanças e utopias na Educação Básica: histórias de vida e experiências docentes, são abundantes de significados, que ora demonstram a esperança de autonomia via escola, ora carregam o desencanto de um sistema que oprime a partir da lógica do capitalismo neoliberal, cuja mácula é a perpetuação das desigualdades de classe social, exclusão, opressão e exploração.

Para lograr o intento da delimitação deste artigo, foram privilegiados os 'dados brutos' coletados no âmbito das entrevistas, que trazem histórias de vida com narrativas de experiências pedagógicas e relatos acerca dos processos de construção da identidade docente no passado e no presente. Aliás, com base nas entrevistas complementares, incluímos as representações dos professores e professoras em prol das lutas em defesa do magistério e, ainda, algumas falas que caracterizam destruições na educação e nas demais políticas públicas e sociais, engendradas pela conjuntura neoliberal e ultraconservadora, que culminaram com o 'golpe à democracia' e à educação, perpetrado pelo governo atual. Em linhas gerais, o golpe trouxe uma plêiade de barbáries e

\footnotetext{
${ }^{2} \mathrm{O}$ Parfor integra um conjunto de políticas públicas do governo federal em parceria com estados, municípios e instituições de ensino superior, para transformar o magistério. O programa oferece, todos os anos, desde 2009, turmas especiais em cursos de licenciatura e em programas de segunda licenciatura, na modalidade presencial, exclusivas para educadores das redes públicas que não possuem formação superior na área em que atuam, conforme exigência da Lei de Diretrizes e Bases da Educação (LDB) (Disponível em http://www.capes.gov.br/educacao-basica/parfor). O objetivo do Diário de Memórias I foi coletar os dados iniciais, visando apreender algumas 'categorias empíricas' e fornecer elementos para dar sustentação à 'segunda etapa da pesquisa', cujos procedimentos teórico-metodológicos se inspiram nas 'histórias de vida e narrativas de experiências', como veremos no decorrer do texto. Atualmente, o Parfor foi substituído pelo Programa de Formação Inicial e Continuada para Professores da Educação Básica (Profic).
} 
violências, que se materializaram na cultura do ódio, que, por sua vez, caracteriza-se pela intolerância e pelo ‘ódio à democracia'. Todo esse 'saco de maldades' e de ódios vorazes do governo atual e de seus aliados neoliberais e hiperconservadores consubstancia-se na destruição dos direitos dos trabalhadores que, por sua vez, materializa-se na reforma da Previdência Trabalhista, em terceirizações, privatizações do patrimônio público, entre outros estragos causados à cidadania brasileira (SILVA, 2017).

Em suma, refletir sobre identidade e mal-estar docentes significa refletir sobre o neoliberalismo, cujas consequências são a violenta destruição do Estado e o 'apagamento' dos direitos sociais. Trata-se, portanto, de uma 'máquina infernal' que se constitui num programa metódico e planejado de destruição da coletividade, sobretudo pela via da violência estrutural da exclusão e do desemprego, constituindo-se, em vista disso, numa "destruição da civilização" (BOURDIEU, 1998, p. 10). Vale lembrar que, apesar de o artigo não versar diretamente sobre a análise da conjuntura ética, política, econômica e social, somos da opinião de que essas destruições vêm impactando e trazendo consequências para a construção da identidade docente e, assim sendo, para um mal-estar docente nas escolas e fora delas.

Postas essas ideias, justificamos que a digressão que versa sobre questões de política nos parágrafos acima se constitui de grande relevância, considerando que achamos impossível estar no campo de pesquisa de forma 'neutra' e indiferente, sem, no mínimo, denunciar e se posicionar criticamente sobre essa tensa e problemática situação de destruição da democracia em que vive o Brasil. Urge lembrar que tudo isso poderá, indelevelmente, repercutir nas políticas educacionais, na identidade docente e, consequentemente, nos processos educativos.

\section{Trabalho, trabalho docente e educação}

Pensar o trabalho docente implica, primordialmente, refletir sobre o conceito de trabalho na perspectiva marxista. Isso porque o trabalho docente, nesse caso, forma sua identidade a partir da totalidade constituída pelo capitalismo, estando, portanto, submetido à sua lógica e às suas contradições. Nesses termos, o trabalho docente não escapa à dupla face do trabalho, isto é, produzir valores de uso e troca. Produz alienação, 
mas também é via de resistência e unidade dos trabalhadores; em suma, formação humana emancipatória.

Aliado a essas ideias, trazemos apontamentos para refletir sobre o trabalho docente no que diz respeito à educação e às repercussões dessa relação sobre a identidade docente. De acordo com Severino (2002), a educação deve preparar os indivíduos para os domínios necessários ao tríplice universo: do trabalho, da sociabilidade e da cultura simbólica. É nesse contexto que o trabalho docente surge como ferramenta mediadora; e o professor, como sujeito operador dessa mediação, o qual vai construindo sua identidade nas relações que estabelece nesse processo.

A educação é uma atividade humana e, conforme Saviani (2006), está diretamente ligada ao trabalho. Para esse educador marxista, a origem da educação coincide, então, com a origem do homem. Na origem da humanidade, a educação era a própria vida, e o trabalho era ensinado ao se trabalhar. Não havia espaços nem pessoas destinadas exclusivamente a essa função, e todos participavam do processo educativo.

Marx (2013) afirma que não há outra maneira de o indivíduo formar-se e desenvolver-se como ser genérico senão pela dialética entre a apropriação da atividade humana objetivada no mundo da cultura, ou seja, tudo aquilo que o ser humano produz em termos materiais e não materiais é a objetivação da individualidade por meio da atividade vital, isto é, o trabalho.

A concepção marxista problematiza o trabalho em seu sentido ontológico e histórico, compreendendo-o, de um lado, como ato de sobrevivência, mas com potencial de se constituir em um ato de emancipação (trabalho concreto), isto é, quando dirigido conscientemente para fins determinados, elaborado pelo intelecto e pela imaginação humana, em suma, como um ato de liberdade e criação livre do homem; de outro lado, pode ser um simples ato de sobrevivência, inconsciente e de caráter reificado e, por isso mesmo, um meio para obter um fim imediato, que se reproduz na vida cotidiana de maneira mecânica e alienada (trabalho abstrato). O trabalho concreto corresponde à unidade da mercadoria (valor de uso), enfim, à dimensão qualitativa das diversas formas de trabalho útil, ao passo que o trabalho abstrato diz respeito ao valor de troca das mercadorias, independentemente das variações das características particulares dos diversos ofícios. O trabalho abstrato, em suma, diz respeito ao dispêndio de energia 
humana ou de trabalho humano, sem levar em consideração as diversas formas que são empregadas. Portanto, é nessa qualidade de trabalho humano abstrato que o trabalho cria o valor das mercadorias (MARX; ENGELS, 1978; BOTTOMORE et al., 1997; CATTANI, 1997).

Postas essas questões, é mister abstrair que, sob a vigência do capitalismo, o trabalho tem sido, para grande parte dos trabalhadores, apenas um instrumento de luta pela sobrevivência, um meio, e não um fim (trabalho socialmente necessário). Desse modo, no âmbito da divisão social de classe, tornou-se meramente 'meio de vida' para a grande maioria (proletariado) e 'meio de acumulação de riqueza' para uma minoria que detém os meios de produção.

Ou seja, o trabalho abstrato é condição de criação de valores cristalizados em cada mercadoria, independentemente do valor de troca que elas possam assumir nas pressões e contrapressões do mercado. Assim, conforma uma identidade do trabalhador (trabalhador da educação) perante o mercado e, em última instância, perante a sociedade (CODO, 1993).

Saviani (1986) discute que o trabalho docente se incorpora no processo de produção do capital, convertendo-se no seu componente variável. Isso significa que o docente, enquanto assalariado, está atrelado à produção de mais-valia ${ }^{3}$, na medida em que está vinculado à formação da força de trabalho. Nesse sentido, ainda que não diretamente produtivo, esse educador marxista também compartilha a ideia de que o trabalho do educador, do professor, está vinculado à lógica produtiva, à lógica do trabalho abstrato. Em contrapartida, há a necessidade de compreender e apreender o trabalho docente como processo humano concreto, determinado pelas formas históricas de produção e reprodução da existência, e isso implica compreender o processo humano inscrito na totalidade do trabalho, tal como se objetiva no modo de produção capitalista, em suma, no trabalho capitalista (KUENZER; CALDAS, 2009).

De modo geral, há implicações oriundas da reestruturação produtiva do capitalismo no trabalho do professor, tais como: os baixos salários, a precarização das

\footnotetext{
${ }^{3}$ Mais-valia é o termo utilizado por Marx em alusão ao processo de exploração da mão de obra assalariada, que é utilizado na produção de mercadorias. Trata-se de um processo de extorsão por meio da apropriação do trabalho excedente na produção de produtos com valor de troca.
} 
condições de trabalho, o aumento das jornadas de trabalho, dentre outras, postas pelas políticas públicas atuais. O trabalho docente estaria se equivalendo ao trabalho proletário ou, em outras palavras, o professor estaria se proletarizando, ou seja, tornando-se, simultaneamente, e cada vez mais, mercador e mercadoria na/da educação.

A educação, na visão neoliberal, faz parte de um negócio e de um mercado, e os profissionais da educação, entre eles os professores, são os operários deste mercado. As instituições privadas acabam vendo na educação uma maneira de lucrar, e o próprio conhecimento acaba sendo uma mercadoria. (COLLET, 2017, manuscrito)

O professor é considerado um trabalhador intelectual, assim como um conjunto de profissionais que têm como objeto de sua atividade as relações sociais. Isso não significa dizer que o professor está liberto da exploração e opressão exercidas pelo capital, em níveis acentuadamente alarmantes, seja pelos capitalistas detentores das instituições de ensino privado, o que fica evidente pelo processo de mercantilização da educação, seja pelo Estado mínimo e neoliberal, que paga salários cada vez mais irrisórios para a satisfação das necessidades básicas de sobrevivência do magistério público. O que se pode concluir, nesse sentido, é que o trabalho dos professores, por estar imerso na lógica perversa e destrutiva do capital, não escapa, portanto, à reificação e à exploração da mercantilização da mão de obra humana.

As reformas educacionais que surgiram na última década no Brasil trouxeram mudanças significativas para os trabalhadores docentes. Essas reformas não atuam somente no âmbito da escola, mas em todo o sistema, repercutindo em mudanças profundas na natureza do trabalho escolar. Na atualidade, novas questões são trazidas ao debate, e as discussões sobre os processos de flexibilização e precarização das relações públicas de emprego e trabalho chegam também ao campo de gestão escolar. As teses sobre desvalorização e desqualificação da força de trabalho, bem como sobre a desprofissionalização e proletarização do magistério, continuam a ensejar estudos e pesquisas de caráter teórico e empírico. Contudo, verifica-se ainda a existência de uma grande lacuna na produção bibliográfica, tanto no que se refere às atuais condições do trabalho na escola quanto no que tange às formas de resistência e conflito que são manifestas nessa organização (OLIVEIRA, 2014). 
As condições do trabalho docente são um dos fatores mais discutidos em todas as ocasiões em que se trata da melhoria do ensino, qualquer que seja a disciplina considerada. Existem vários elementos que impactam nas condições do trabalho docente; para uma análise/reflexão crítica, poder-se-ia citar: as condições físicas das escolas e a relação com os professores; as condições profissionais dos docentes; o sistema burocrático que é imposto aos docentes; os controles externos sobre o trabalho docente e as implicações do projeto político-pedagógico do governo. Esses fatores trazem como consequências o estresse do docente, a queda da qualidade da sua aula, a impossibilidade de se aperfeiçoar constantemente e a falta de tempo para preparar e refletir criticamente sobre sua prática pedagógica. Os profissionais sentem o desgaste físico e/ou mental de longas jornadas de trabalho, que são necessárias diante da baixa remuneração e para a obtenção de um padrão de vida razoável.

Considerando a ideia central deste texto, qual seja, conceituar o trabalho à luz da perspectiva marxista destacando as suas dimensões ontológicas e epistemológicas, ao discorrer sobre trabalho docente e identidade, veremos que o trabalho é uma categoria central do ser social, uma vez que “[...] nunca abandona suas origens, ao mesmo tempo em que se inscreve na história dos homens: na medida em que ele mesmo significa a história dos homens" (CODO, 1993, p. 117).

Ademais, aliada ao conceito de trabalho, situa-se a reflexão sobre o conceito de identidade. Este, por sua vez, não pode ser deslocado do conceito de trabalho em geral nem do trabalho docente. Isso é perceptível nas falas dos professores, quando afirmam que

[...] a identidade docente é algo que caracteriza o professor nos seus diversos aspectos: docente, político, ideológico, nas questões de luta, de enfrentamento, portanto esta construção da identidade é resultado, fruto, e desencadeada por estas participações do professor nas diversas ações do cotidiano, pra além da sala de aula, nas suas relações sociais. (FERREIRA, 2014, p. 278, grifo nosso)

Nesse sentido, emergem algumas questões ligadas ao método materialista histórico-dialético: como os docentes podem se identificar com um sistema que desvaloriza, explora e ignora a importância social e política do trabalho docente? Como os 
docentes podem se identificar com o sistema capitalista, dividido em classes sociais antagônicas, cujos fundamentos ontológicos, epistemológicos e sociais se assentam na educação sob as dimensões do trabalho abstrato e do trabalho produtivo, que gera mercadoria e valor de troca e, consequentemente, na perspectiva do corpo produtivo, tem a finalidade de reproduzir a lógica do capital, tornando-o cada vez mais rentável?

Antes de mais nada, vale lembrar que o conceito de identidade docente está dialeticamente mediado pelas condições objetivas das práticas educativas dos docentes, que atuam nas salas de aula e fora delas. Todo esse processo identitário perpassa os aspectos da concentricidade das práticas formativas. A identidade docente diz respeito, sobretudo, ao desencanto dos professores com as políticas educacionais neoliberais, que promovem o mal-estar docente e, nessa perspectiva, a desistência da educação pelos trabalhadores docentes, uma vez que estas engendram a precarização e destruição da educação.

A identidade pressupõe uma rede intricada de representações, que permeia todas as relações, na qual cada identidade reflete outra identidade, desaparecendo qualquer possibilidade de se estabelecer um fundamento originário para cada uma delas. Assim sendo, a identidade possui um jogo de múltiplas reflexões que estrutura as relações sociais. Esse jogo é mantido pela atividade dos indivíduos, de sorte que "[...] é lícito dizerse 'identidades', as quais refletem no seu conjunto a estrutura social e, ao mesmo tempo, reagem sobre ela, conservando-a ou transformando”. Sendo assim, “[...] a identidade que se constitui no produto de um permanente processo de identificação aparece como um dado e não como um dar-se constante que expressa movimento" (CODO, 1993, p. 116-117, grifo nosso).

A identidade pressupõe uma lei da dialética, que é o movimento e apreensão do real concreto, vivido e apreendido no movimento e na metamorfose da história. Nesses termos, torna-se impossível estudar identidade na ausência da história, sendo, portanto, inútil descolar a categoria da identidade da categoria 'atividade' e, neste caso, da atividade docente (CODO, 1993, p. 116-117). Em suma, a identidade deve ser pensada tomando-se como objeto de análise o indivíduo; e este, em sua individualidade histórica. De fato, a identidade de "[...] cada trabalhador, em sua singularidade, pode revelar seu cotidiano de trabalho, tomando como referência seu próprio fazer produtivo e a forma da 
apropriação desse fazer pela unidade capitalista de produção a que se integra" (CODO, 1993, p. 122-123).

Quando se fala em identidade, profissão (ou profissionalidade), as narrativas trazem divergências no que diz respeito às especificidades da profissão docente.

\begin{abstract}
Hoje em dia ser professor é salvar vidas. Você precisa saber um pouco de tudo. Você é mãe, psicóloga, médica. Ser professor é lutar contra o desgaste, o desinteresse, a agressividade, a falta de valores dos alunos. A ausência da família joga para a escola muitas das funções que deveriam ser de casa. Às vezes, a última coisa que eu faço é dar aula. Tenho aluno com fome, alunas (adolescentes) grávidas, usuários de drogas, tudo isso na escola, dentro da sala, na minha aula de quarenta e cinco minutos. (ZAMPIERON, 2014, p. 223, grifo nosso)
\end{abstract}

Dito de outro modo, as representações sobre identidade docente revelam como há uma dialética entre individual e coletivo, universal e particular, quando está em jogo a construção da identidade no limiar dos aspectos contraditórios da prática docente cotidiana. Nesse sentido, pode-se falar, de um lado, de identidades, no sentido mais abstrato, e, de outro, de uma identidade concreta, que traz consigo as mazelas destrutivas das políticas educacionais neoliberais, em cujo espelho reverbera a reprodução do capitalismo, que tudo regula por meio da mercadoria (mercantilização da educação); em suma, a produção de mais-valia e, na prática, a produção das desigualdades sociais, que engendram as desigualdades escolares.

\title{
3. Identidade docente em crise: o mal-estar do corpo produtivo
}

Discorrer sobre educação, trabalho, identidade e mal-estar demanda trazer o debate sobre trabalho produtivo e, consequentemente, sobre o corpo produtivo dos docentes. Trata-se de uma questão de suma relevância, considerando as relações entre identidade e cotidiano do trabalho docente. De fato, a crise do capital, que gera a crise e a destruição da educação, e outras políticas públicas e sociais podem ser sentidas, cotidianamente, através do desmonte e da precarização das políticas educacionais. A precarização do trabalho docente se traduz naquele fenômeno que se convencionou chamar de 'mal-estar docente', que, no Brasil, atinge todos os níveis de ensino 
(fundamental, médio e superior). Aborda também as memórias das práticas pedagógicas historicamente desenvolvidas nas escolas, num ímpeto de utopia e esperança. O malestar docente, em suas consequências concretas, abrange o absenteísmo trabalhista e o abandono da profissão docente, promove repercussões negativas da prática docente sobre a saúde destes, transformando-a em uma prática insalubre, ao invés de uma atividade emancipatória (ESTEVES, 1999).

Posto isso, quando se fala de identidade docente em crise: um mal-estar do corpo produtivo, faz-se necessário destacar que não se trata apenas de uma crise do trabalho, da identidade docente, enfim, da educação em si, mas de uma crise estrutural do capital, que reverbera e se materializa nas políticas públicas e sociais, e, nesse bojo, uma crise das políticas educacionais neoliberais.

Portanto, nesses meandros das crises cíclicas do capital, os processos de formação e construção da identidade docente se circunscrevem à reflexão sobre o trabalho produtivo e à construção do corpo produtivo dos professores e professoras. É na perspectiva ontológica e epistemológica que o trabalho produtivo pode ser abstraído como trabalho humano abstrato, e não como atividade humana vital e emancipatória. Trata-se, portanto, do trabalho abstrato, que opera no corpo social como 'corpo produtivo", isto é, corpo que trabalha com o fim único de manter-se e "[...] satisfazer as meras necessidades necessárias" (MARX, [19--] apud ANTUNES, 1995, p. 126). O corpo do trabalhador é considerado produtivo à medida que produz capital, entra no circuito de mercadorias, realiza mais-valia, entra em circulação, e isso porque, no capitalismo, só é produtivo o operário que produz mais-valia para o capitalista, ou que trabalha para tornar rentável o capital (RUBIN, 1987).

Em suma, o corpo é produtivo porque é engendrado por intermédio da mediação entre o corpo biológico e o corpo social. O corpo produtivo, portanto, consolida-se na prática social, por meio da mediação entre o social e o biológico, sob a égide do trabalho socialmente necessário, cujo objetivo único é trabalhar para manter-se e satisfazer as necessidades básicas e, consequentemente, produzir/trabalhar e reproduzir o capital. Dito de outra forma, o trabalho produtivo, do ponto de vista capitalista, cria valor e mais-valia ou “trabalho produtivo de mais-valia” (GUÉRY; DELEULE, 1972). O corpo produtivo é aquele que trabalha enquanto produtor de mercadorias e desigualdades sociais, ele próprio como 
mercadoria (corpo-objeto), sobretudo quando aparece sob a forma de valor de troca. Nesses termos, o corpo que trabalha, ao produzir mercadorias, mercadorizando-se, coisifica-se. Perde, portanto, a sua especificidade e o vínculo estreito que mantinha com a subjetividade do trabalhador, deixando de ser o metabolismo entre o homem e a natureza para plasmar uma outra identidade, uma outra subjetividade: a de vendedor da força de trabalho (CODO, 1993). Os trabalhadores da educação estão imersos nas crises cíclicas ou 'crise estrutural do capital', que deixam marcas agudamente destrutivas para a humanidade e, no caso dos professores, de maneira insofismável.

São marcas inerentes ao sistema sociometabólico do capital. São marcas oriundas das políticas educacionais insuficientes e precárias que podem ser percebidas no cotidiano das práticas educativas dos professores e, de forma geral, na vida social. Os educadores mobilizam as suas capacidades físicas, cognitivas e afetivas para atingir os objetivos na realização do trabalho pedagógico, que, na maioria das vezes, gera sobrecarga e elevado nível de esforço de suas funções psíquicas. Diante dessa realidade, os professores apresentam sintomas clínicos que justificam os elevados índices de absenteísmo por comprometimento à saúde e por desencanto pela profissão.

De fato, as falas deixam claros a angústia e o processo de sofrimento do trabalho docente e a consequente sensação de desistência da educação, no que se refere à organização da escola e do trabalho pedagógico. "Eu estava chegando na escola e li escrito no chão do asfalto 'o pior de todos os espaços' e uma flechinha apontava para a escola. Meu Deus, é o local que eu trabalho e os alunos escrevendo isso. O que está acontecendo com a escola?" (ZAMPIERON, 2014, p. 224, grifo nosso).

As narrativas trazem uma plêiade de problemas, que podem ser considerados justos reclamos, vindos dos docentes que atuam na Educação Básica. Elas apontam a ausência da família, a falta de interesse dos alunos, as irresponsabilidades dos órgãos competentes, a precariedade da estrutura física das escolas, entre outros, como os principais fatores de desencanto e, consequentemente, do mal-estar que vem caracterizando a profissão docente. Segundo a professora, "a sociedade se acostumou, parece que tem o prazer de colocar tudo na escola". 
Tem Conselho Tutelar, CRAS [Centro de Referência da Assistência Social], CAPS [Centro de Atenção Psicossocial], Promotoria, quatro instituições que depositam tudo o que é problema na escola, pra nós darmos conta. Tem 35, 37 alunos por turma, e eles estão lá, e eu não posso sempre dar a atenção que eles precisam, porque eu tenho mais alunos. $O$ que é justo então? (COLLET, 2017, manuscrito)

De acordo com Esteves (1999), a situação de trabalho dos professores é desconfortável e precária, pois não há estrutura física adequada, tampouco recursos materiais satisfatórios para otimizar o objetivo da prática docente, ou seja, o processo ensino-aprendizagem. Para o autor, tal condição de trabalho resulta em alterações na saúde do professor, desencadeando, nos educadores, sintomas de esgotamento físico e mental, perturbações do sono, estresse, aumento dos sintomas de ansiedade, depressão, irritabilidade, sentimento de culpa, desesperança, desmotivação e impotência diante do fracasso escolar dos alunos. Para Esteves (1999), quando o professor apresenta esses sintomas e sentimentos, passa a utilizar mecanismos de defesa, tais como absenteísmo, solicitação de atestados e/ou licenças médicas e licenças sem vencimento, para lidar com a realidade advinda da sua prática.

$\mathrm{Na}$ verdade, trata-se do processo de sofrimento no trabalho ou 'mal-estar docente', que gera diversas doenças, que causam impactos sobre a vida cotidiana do professor dentro e fora da escola. O sofrimento bloqueia a relação do trabalhador (da educação) com a organização do trabalho pedagógico. E é assim que começa: a energia pulsional, que não acha descarga no exercício do trabalho, no caso do trabalho pedagógico, acumula-se no aparelho psíquico, ocasionando sentimentos de desprazer, tensão e angústia, propiciados pela dimensão somática das cargas psíquicas excessivas (DEJOURS; ABDOUCHELI; JAYET, 1994). Desse modo, em virtude das cargas psíquicas em outros compartimentos do organismo, há tanto fadiga psíquica, ou nervosa, quanto fadiga física. Nesse sentido, "[...] a fadiga é uma testemunha não específica da sobrecarga" que pesa sobre um ou mais setores do organismo psíquico e somático. Tal “princípio de difusão” é válido nos dois sentidos: a carga psíquica pode ter traduções viscerais ou musculares, mas o inverso é verdadeiro (DEJOURS; ABDOUCHELI; JAYET, 1994, p. 29-31). 
O contexto do sofrimento no trabalho docente e do mal-estar docente no âmbito das políticas neoliberais da atualidade é mediado pela urgência em transmitir conteúdos curriculares isolados das necessidades dos estudantes; pela falta de capacidade para lidar com as inúmeras demandas educacionais; pela importância de manter a atenção e o engajamento dos estudantes no processo de ensino-aprendizagem; pelas condições desfavoráveis para o exercício da profissão; pelas exigências da sociedade por mais escolarização da população e qualidade da educação; pela sobrecarga de trabalho; e pela desvalorização social e profissional. Esses fatores atuam na dinâmica de prazer e sofrimento no trabalho docente e geram risco para a saúde dos professores. Esse processo de sofrimento e de degradação do trabalho docente também se verifica pela fadiga e pelo estresse, pelas cargas excessivas de trabalho em sala de aula, pelo grande número de alunos nas salas, pelos problemas de gestão da escola, pelos espaços escolares precários e por outros fatores (DEJOURS; ABDOUCHELI; JAYET, 1994; FREITAS, 2013).

Como é possível perceber, são inúmeros os fatores que provocam este fenômeno do mal-estar presente na profissão docente. Esteves (1999) compreende que o conceito de mal-estar docente é um fenômeno que sofre influência de fatores sociopolíticos, pessoais e da formação profissional.

Este mal-estar concretiza-se no professor como consequência de um “estranhamento" (FREITAS, 2013). Ou seja, os professores sentem-se incapazes diante do que Ihes é cobrado e da incapacidade de realizá-lo. Um sentimento de inutilidade. Mal remunerados, não conseguem acompanhar a 'moda' imposta pela sociedade, são tachados de antiquados e, muitas vezes, de 'caretas' pelos adolescentes. Exaustos do trabalho, não desfrutam nem mais do lazer e das delícias que o tempo livre oferece. Em muitos casos, encontramos professores que têm vergonha de dizer qual é sua profissão ou até mesmo de falar do seu trabalho. "Até nós, professores, ficamos confusos quando discutimos esta contradição, minha profissão forma todas as outras, mas ao mesmo tempo é uma das menos valorizadas, pelo Estado, muitas vezes pelas famílias e pelos nossos alunos [...]" (ZAMPIERON, 2014, p. 226, grifo nosso). Ou seja, fatores internos e externos contribuem para um mal-estar generalizado, sob a forma de declínio da imagem, tendo repercussões óbvias na condução pedagógica, na dimensão pessoal e profissional desses educadores, materializando-se numa crise de identidade. 
Para Dejours (1999), um dos mais cruéis golpes que o homem sofre com o trabalho é a frustração de suas expectativas iniciais, à medida que a propaganda do mundo do trabalho promete felicidade e satisfação, pessoal e material, para o trabalhador; porém, quando lá adentra, o que se tem é infelicidade e, na maioria das vezes, a insatisfação pessoal e profissional, desencadeando, então, o sofrimento humano nas organizações. As relações de trabalho, dentro das organizações, frequentemente, despojam o trabalhador de sua subjetividade, excluindo o sujeito e fazendo do homem uma vítima. "O sofrimento aumenta porque os que trabalham vão perdendo gradualmente a esperança de que a condição que hoje Ihes é dada possa amanhã melhorar.” (DEJOURS, 1999, p. 17).

Nesse sentido, poder-se-ia dizer que a vida do professor sintetiza dois "sentidos contraditórios" (paixão e sofrimento), que podem ser resumidos na palavra "paixão", ou melhor, na dimensão da "educação, paixão e compromisso" (SAVIANI, 2010, p. 134). Trata-se de paixão enquanto envolvimento afetivo, amor profundo, entusiasmo muito vivo, dedicação extremada a uma causa, enfim, "compromisso radical carregado de afetividade" (SAVIANI, 2010, p. 134). Para além da paixão, enquanto compromisso radical eivado de afeto, a vida do professor pode ser de sofrimento e padecimento. Nessa linha de reflexão,

[...] ser professor hoje em dia envolve esses dois significados, e parece mesmo que a própria política governamental manifesta esse entendimento ao cobrar dos professores extrema dedicação e responsabilizando-os pelo fracasso escolar e, ao mesmo tempo, submetendo-os a condições precárias de trabalho com salários aviltantes. (SAVIANI, 2010, p. 134)

Na busca de entender o que está ocorrendo no âmbito de trabalho do professor, deparamo-nos com a síndrome de Burnout, que, em sentido literal, significa queimar de dentro para fora. Burnout simboliza a perda do fogo, da vontade, do desejo de continuar na luta: “Falta de motivação, desamparo, desesperança, passividade, alienação, depressão, fadiga, estresse e agora Burnout, em última instância se defrontam com a mesma questão: por que as pessoas desistem?” (CODO, 1993, p. 239). Diante das dificuldades cotidianas, os docentes vão sendo encurralados entre o que desejam e o que podem fazer, entre as vitórias e as frustações, entre as possibilidades e os obstáculos. Por esse fim, a síndrome de Burnout também é conhecida como 'síndrome da desistência'. A 
síndrome é entendida como um conceito multidimensional, que envolve três componentes: “[...] exaustão emocional, despersonalização e falta de envolvimento pessoal no trabalho" (CODO, 1993, p. 238).

O professor que acreditou na capacidade transformadora da educação, e por isso mesmo investiu toda a sua energia num projeto de ações que levariam às transformações imaginadas, com o passar dos anos, vai percebendo o quão longe ainda se encontra da sua utopia. Essa percepção acaba por levá-lo ao desânimo e, muitas vezes, à desistência. O Burnout é uma desistência de quem muito lutou, mas que, sob o próprio olhar crítico, pouco realizou. A impossibilidade de realizar os seus sonhos desmonta o professor, quando ele se sente impossibilitado de fazer o que deveria; surge então um conflito, cuja dinâmica permite a instalação do Burnout. "A síndrome da desistência resume, de forma clínica, a perversa fisionomia de desencanto na escola." (GENTILI; ALENCAR, 2003, p. 19).

As novas exigências e responsabilidades, associadas ao tempo e aos recursos disponíveis, contribuem também para um mal-estar e para uma ansiedade difíceis de suportar, influenciando, dessa forma, o ambiente profissional e a imagem do professor.

Tem que ir na sala e dar conta de 30, 35 alunos, dar conta... são 30, 35 pessoas diferentes, mais os familiares que o professor precisa dar conta sozinho. Não tem ajuda, não tem apoio de ninguém. Em algumas escolas, nem o coletivo não aceitam mais... o planejamento coletivo que era uma ferramenta de apoio, troca de ideias, proibiram nós [sic] de trabalhar o coletivo. (COLLET, 2017, grifo nosso, manuscrito)

O individualismo e a solidão são fatores que provocam o mal-estar docente e, consequentemente, o adoecimento do professor ou até mesmo a desistência da profissão, além da falta de condições objetivas de trabalho (baixos salários, relações precárias de trabalho, falta de formação permanente, de recursos materiais, problemas no currículo, má gestão da escola, entre formas de precarização). Os professores têm poucas oportunidades para partilhar as suas preocupações e analisar sua própria atividade profissional coletivamente com seus colegas. A troca de experiência dá lugar ao livro didático e à mera reprodução de conteúdos elitistas, gerenciados pelos órgãos públicos em nome da ordem e do progresso. 
O individualismo, fragmentado e influenciado pela lógica organizacional (arquitetura, horário, carga docente, entre outros), contribui para que os professores "olhem apenas para si", interagindo pontualmente com os colegas, pois qualquer necessidade de mais partilha é contrária ao individualismo.

É muita carga, tudo recai para o professor. Aí está o desencanto. O professor não dá mais conta sozinho. Por que vem o desencanto para o professor? Porque quem tem a máquina nas mãos não se preocupa com a educação, não quer fazer da educação uma ferramenta de transformações. (SOTILI, 2017, grifo nosso, manuscrito)

A falta de um trabalho coletivo nas escolas é mencionada nas narrativas como fator negativo para o trabalho docente. A identidade dos profissionais vem se construindo a partir de práticas isoladas. "O sistema capitalista está tirando a sensibilidade dos seres humanos, tirando a humanização [...] está desumanizando, e trabalhar com educação é humanizar as pessoas, é construir as pessoas" (COLLET, 2017, manuscrito). São poucas as escolas que apresentam uma proposta coletiva de trabalho, e isso influencia diretamente na saúde dos professores. As discussões que ocorrem entre os docentes no seio do coletivo consistem efetivamente em um produtivo debate que, de fato, tem foco, ao mesmo tempo, na realização do trabalho pedagógico e na promoção da melhoria contínua de sua qualidade. Em um contexto de trabalho docente coletivo, a experiência profissional se desenvolve e é compartilhada pelos antigos com os mais novos, e isso só pode resultar em um coletivo laboral que se consolida cada vez mais e beneficia tanto a saúde dos professores quanto a formação política e profissional.

O professor, trabalhador como tantos outros, encontra-se nesta vitrine do sofrimento. O medo de não satisfazer, de não estar à altura das imposições do trabalho (horário, ritmo, formação, aprendizagem dos alunos, instruções, diplomas, experiências, rapidez na aquisição de conhecimentos práticos e teóricos) (DEJOURS, 1999) torna-o um profissional desencantado, doente, que sofre com as exigências mercadológicas, sofrimento este não só do corpo, mas, também da alma. A pressão por resultados interfere no trabalho e na vida dos docentes; o estresse, a falta de estrutura e os baixos salários são fatores que interferem no desencanto profissional. 
É preciso ficar claro que desesperança não é maneira de estar sendo natural do ser humano, mas distorção da esperança. Eu não sou primeiro um ser da desesperança a ser convertido ou não pela esperança. Eu sou, pelo contrário, um ser da esperança que, por 'n' razões, se tronou desesperançado. Daí que uma das nossas brigas como seres humanos deva ser dada no sentido de diminuir as razões objetivas para a desesperança que nos mobiliza. (FREIRE, 1996, p. 81)

A esperança e o encantamento, segundo Freire (1996), são exigências do ato de ensinar. A esperança faz parte da natureza humana, e seria uma contradição se o ser humano não participasse, durante sua história, de uma constante busca e do movimento animado pela transformação da situação de imobilismo em perspectiva de utopia e esperança.

Gentili (2008, p. 111) nos adverte: “[...] a esperança não é um bem que se obtém, uma coisa conquistada no final de um caminho, mas sim uma utopia viável que se constrói coletivamente". Tampouco uma história se fortalece sem o ímpeto da esperança, e nós professores somos “militantes da esperança” por excelência (GENTILI; ALENCAR, 2003).

Nessa direção, o sentido que se quer atribuir ao termo esperança é sinônimo de busca e de ação, de militância político-prática, de 'resistência ativa' e, portanto, movimento da história. É urgente e politicamente relevante superar a ideia de esperança em oposição à passividade ou espera. A nosso juízo, a definição mais apropriada talvez seja aquela elaborada pelo educador crítico Paulo Freire: esperança, do verbo esperançar, não do verbo esperar; a esperança enquanto construção, do ir à luta, do levar à diante, do não desistir, do resistir ativamente (VALMORBIDA, 2016).

Diante dessas colocações, não podemos deixar de referenciar teoricamente o significado da expressão "resistência ativa", definida por Saviani (2015) e Valmorbida (2016) como o processo de mobilização, de forma individual e coletiva, que pretende formular um conteúdo alternativo às medidas vigentes, mas que, fundamentalmente, não se limite a manifestar discordâncias, críticas e objeções. A resistência ativa, na assertiva de Saviani (2015), busca a superação do caráter passivo, a superação das práticas apenas discursivas e, desse modo, configura-se em militância, em superação do desencanto e, consequentemente, em aspecto de utopia e esperança. 


\section{Conclusões provisórias}

Como já nos referimos na introdução, o artigo buscou refletir e problematizar as relações entre trabalho identidade e mal-estar docente no contexto da Educação Básica, no intuito de pensar essa problemática no âmbito das memórias de desencanto e esperança presentes nas narrativas de professores do passado e do presente da região Oeste de Santa Catarina. Sendo assim, torna-se essencial responder à pergunta-problema: 'em que medida trabalho, mal-estar docente e identidade se amalgamam no cotidiano das práticas pedagógicas?' Além disso, urge recuperar as questões de pesquisa que, didaticamente, desdobraram-se da pergunta-síntese: ‘o que é trabalho e suas relações com a educação?', 'o que é o trabalho docente, trabalho produtivo e, nessa esteira, o que é corpo produtivo docente?', 'como os professores o realizam, tendo como mediadora a identidade e a construção do mal-estar docente?', 'como os docentes podem se identificar com um sistema que desvaloriza, explora e ignora a importância social e política do trabalho docente?'.

De todo esse processo indagativo, no qual abordamos os processos que abarcam o trabalho, a identidade e o mal-estar docente e, consequentemente, a influência desse mal-estar nas práticas pedagógica, emergiram os seguintes pontos, destaques e 'achados', além de indicações para reflexão e continuidade das pesquisas sobre a problemática investigada:

- A identidade docente perpassa muitos aspectos do labor docente, ou seja, está intrinsicamente ligada às condições objetivas para a realização do trabalho docente. Nessa linha de debate, destaca, em termos de reflexão, a identidade dos professores está intimamente ligada ao modo como o trabalho no âmbito do capitalismo é concebido e praticado. Referimo-nos à positividade e à negatividade do trabalho docente sob a égide do capital, cujas dimensões epistemológica e ontológica se assentam na perspectiva do trabalho abstrato (valor de troca), e não do trabalho concreto (valor de uso);

- A partir dessas premissas, pode-se dizer que a identidade docente está indelevelmente ligada ao desencanto dos professores com as políticas educacionais neoliberais, com o mal-estar docente, que promove a desistência da educação. Essas ideias sobre a identidade docente pressupõem uma miríade de 
representações, que permeia todas as relações, em que cada identidade reflete outra identidade, desaparecendo qualquer possibilidade de se estabelecer um fundamento originário para cada uma delas;

- A identidade possui um jogo de múltiplas reflexões que estrutura as relações sociais. Além disso, ela pressupõe uma lei da dialética, que é o movimento e apreensão do real concreto, vivido e apreendido no movimento e na metamorfose da história. Portanto, é impossível estudar identidade na ausência da história, sendo inútil descolar a categoria identidade da categoria 'atividade' e, nesse caso, da atividade docente, bem como, consequentemente, separar a identidade do processo histórico (modo de produção capitalista, em que ela está inserida). Em linhas gerais, a identidade deve ser pensada tomando-se como objeto de análise o indivíduo, que deve ser sempre pensado em sua individualidade histórica;

- A identidade compreendida nas narrativas dos professores revela desconforto e constrangimento com o cotidiano das práticas pedagógicas nas escolas. Esse processo histórico de desvalorização da docência é mediado pela falta de estrutura, problemas de gestão escolar, escassez de material, formação descontinuada e precária, educação de baixíssima qualidade, além de perseguições e represálias nos momentos de luta em defesa dos direitos, nos momentos de greve, medos e sofrimentos. Essas representações sobre a identidade desvelam que há uma dialética entre individual e coletivo, universal e particular, quando está em jogo a construção da identidade no limiar do fazer produtivo no contexto do sistema capitalista, produtor de capital, mercadorias e mais-valia;

- O professor, ao não se identificar com a natureza do próprio trabalho, torna-se estranho à própria profissão que realiza, na dimensão da 'objetivação genérica do homem'. Esta faz dele um ser alheio a si próprio, ou seja, o homem aliena-se do próprio homem, aliena-se do produto da sua atividade vital - o trabalho, a educação. Nesse sentido, a alienação se impõe como fator de dominação sobre o trabalho humano (trabalho docente) e refere-se a alguma forma de perda, de privação por parte desses sujeitos, cuja consequência é o 'desgaste das faculdades físicas e da mortificação dos demais campos da experiência humana (cultural e intelectual)', considerando as mazelas do 'mal-estar docente'; 
- As reformas educacionais das últimas décadas têm repercutido sobre a organização escolar, provocando uma reestruturação do trabalho docente, com efeitos diretos no modo de execução das atividades, o que repercute na saúde dos profissionais. As mudanças no mundo do trabalho têm alterado significativamente o processo de educação e a saúde dos trabalhadores, sobretudo porque a educação implica, necessariamente, a relação com o outro. Decorrente disso, encontramos no espaço escolar um profissional docente fatigado, doente, desencanto com a profissão que exerce;

- Dentre as doenças que acometem os docentes atualmente, encontram-se as doenças físicas (varizes, calos nas cordas vocais, rouquidão, problemas na coluna, alergias), de mais fácil constatação, porém precisamos focar mais nas doenças silenciosas, que minam a capacidade física e mental dos docentes. O Burnout, reconhecido em vários países e em diversos ramos de atividade profissional sobretudo naqueles que exigem intenso envolvimento emocional e mental com o trabalho e suas relações sociais -, talvez seja a mais ameaçadora e devastadora doença profissional de nossa época. Ele está intimamente ligado à depressão, mas suas causas são específicas do fazer laboral. Torna-se urgente pensar a escola na condição de ambiente de trabalho dos profissionais da educação, em uma nova dinâmica de relações interpessoais, de tempo, espaço e projeto pedagógico, para que a doença seja atacada em sua raiz;

- Em referência às práticas pedagógicas dos docentes no momento atual, bem como à condução do processo ensino-aprendizagem na sociedade contemporânea, é preciso ter como premissa a necessidade de uma reformulação pedagógica que priorize uma prática formadora para o desenvolvimento, em que a escola deixe de ser vista como uma obrigação a ser cumprida pelo aluno e se torne uma fonte de efetivação de conhecimento intelectual que o motivará a participar do processo de desenvolvimento social, não como mero receptor de informações, mas como idealizador de práticas que favoreçam esse processo. Gadotti (2000, p. 8) afirma que, seja qual for a perspectiva que a educação contemporânea tomar, uma educação voltada para superação desse novo tempo será sempre “[...] uma educação contestadora, superadora dos limites impostos 
pelo Estado e pelo mercado, portanto, uma educação muito mais voltada para a transformação social do que para a transmissão cultural".

Em vista do exposto, cabe concluir este artigo de forma propositiva - sobretudo considerando os desafios para a formação de professores, no que se refere à construção da identidade, no âmbito da destruição dos direitos dos trabalhadores em geral e da educação e das políticas públicas e sociais, a partir do golpe à democracia engendrado e tramado pelas elites neoliberais e ultraconservadoras capitaneadas pelo governo atual, Congresso Nacional, Senado, mídia burguesa e grande parte da justiça brasileira -, deixando o seguinte recado: precisamos, enquanto intelectuais críticos, transformadores e revolucionários, refletir, dialogar e agir, isto é, compreender o que há por trás de determinadas ideologias que surgem para corromper os ideais democráticos, pois “[...] seria uma atitude ingênua esperar que as classes dominantes desenvolvessem uma forma de educação que proporcionasse às classes dominadas perceber as injustiças sociais de maneira crítica" (FREIRE, 2005, p. 45).

Nesse sentido, encerramos finalmente com as "oito tarefas", ou desafios essenciais, propostos por Apple (2011, p. 15) para que o educador possa pensar uma educação para além do capital, em outro processo formativo, de caráter mais crítico, permanente e contínuo, além de propositivo e revolucionário; em suma, com perspectiva de coletividade e da totalidade. Quais sejam:

1) Dar "testemunho da negatividade", denunciando as práticas educacionais ligadas às relações de poder e dominação;

2) Apontar as contradições e os espaços de ações possíveis;

3) Atuar como assessores dos grupos de pessoas e dos movimentos sociais engajados em questionar as atuais relações desiguais;

4) Argumentar sobre a importância de não se jogar fora o "conhecimento de elite", mas reconstruir sua forma e seu conteúdo a serviço das necessidades sociais;

5) Manter vivas as tradições do trabalho radical. Discutir as "memórias coletivas" no sentido de mantê-las vivas ou criticá-las;

6) Criticar e dialogar criticamente exige reaprendizagem e desenvolvimento, de acordo com a realidade e o grupo; 
7) Agir em conjunto com os movimentos sociais progressistas. Devemos participar e dar nosso conhecimento especializado aos movimentos que se voltam às lutas por uma política de redistribuição e por uma política de reconhecimento;

8) Usar o privilégio de ser um estudioso/ativista para abrir espaços em universidades e em outros lugares, "como nas escolas de educação básica onde atuamos diariamente com indivíduos em busca de humanização" (grifo nosso).

Quando se observam as narrativas nas entrelinhas e os aportes teóricometodológicos subjacentes às reflexões, chega-se à conclusão de que há a necessidade de superação das relações entre trabalho e identidade docente, forjadas na relação e na contradição dialética, entre desencanto e esperança na profissão docente. Além do mais, apontam para a necessidade de uma educação 'para além do capital', engendrada nos espaços de luta e resistência por uma educação de qualidade para todos.

Urge exigir das políticas educacionais que: cumpram o papel do Estado, não responsabilizem e culpabilizem os professores pelo fracasso escolar e não os submetam às condições precárias de trabalho com salários aviltantes. Diante disso, “[...] 'importa' que os professores estejam conscientes dessa situação contraditória e se disponham a organizar-se e lutar para mudar a ordem das coisas" (SAVIANI, 2010, p. 134).

Ao fim e ao cabo, uma provocação poética de Bertolt Brecht aos professores que participaram da pesquisa e a todos aqueles que militam nas escolas e sindicatos de professores, que constroem suas identidades na lógica do capital, do mal-estar docente, mas também no limiar da dialética do desencanto/desistência e da esperança:

Os esperançosos

Pelo que esperam? Que os surdos se deixem convencer

E que os insaciáveis

Devolvam-lhes algo? Os lobos os alimentarão, em vez de devorá-los! Por amizade

Os tigres convidarão A lhes arrancarem os dentes! É por isso que esperam! (BRECHT, 2000, p. 102) 
A resposta pode ser dada reiterando os versos do poema de Manuel Alegre:

Canção do vento que passa Mas há sempre uma candeia Dentro da própria desgraça Há sempre alguém que semeia Canções no vento que passa. Mesmo na noite mais triste

Em tempos de servidão Há sempre alguém que resiste Há sempre alguém que diz não.

(ALEGRE, 2005, p. 98)

\section{Referências}

ALEGRE, Manuel. Praça da canção. Lisboa: Dom Quixote, 2005.

ANTUNES, Ricardo. Adeus ao trabalho. Campinas: Unicamp, 1995.

APPLE, Michael W. (org.). Educação crítica: análise internacional. Porto Alegre: Artmed, 2011.

BRECHT, Bertholt. Poemas 1913-1956. Tradução e seleção Paulo César de Souza. São Paulo: Ed. 34, 2000.

BOTTOMORE, Tom et al. Dicionário do pensamento Marxista. Rio de Janeiro: Jorge Zahar, 1997.

BOURDIEU, Pierre. Contrafogos: táticas para enfrentar a invasão neoliberal. Rio de Janeiro: Zahar, 1998.

CATTANI, Antonio David. Trabalho, tecnologia: dicionário crítico. Petrópolis: Vozes, 1997.

CODO, Wanderley (org.). Indivíduo, trabalho e sofrimento: uma abordagem interdisciplinar. Petrópolis: Vozes, 1993.

COLLET, Zenaide. Entrevista Complementar. [Entrevista cedida a] Alcione Maria Bevilaqua. Quilombo, 24 abr. 2017. Manuscrito.

DEJOURS, Christophe. A banalização da injustiça social. Rio de Janeiro: Fundação Getúlio Vargas, 1999.

DEJOURS, Christophe; ABDOUCHELI, Elizabeth; JAYET, Christian. Psicodinâmica do Trabalho: contribuições da Escola Dejourniana à análise da relação prazer, sofrimento e trabalho. São Paulo: Atlas, 1994. 
ESTEVES, José Manuel. 0 mal-estar docente: a sala de aula e a saúde dos professores. São Paulo: Editora Edusc, 1999.

FERREIRA, Aurélia Batista. Entrevista. In: SILVA, Maurício Roberto da et al. Entre Esperanças e Utopias na Educação Básica: histórias de vidas e experiências docentes. 1. ed. Chapecó SC: DR Publicidade, 2014. v. 1, p. 273-279.

FREIRE, Paulo. Pedagogia da autonomia: saberes necessários à prática educativa. 21. ed. São Paulo: Paz e Terra, 1996.

FREIRE, Paulo. Pedagogia do Oprimido. Rio de Janeiro: Paz e Terra, 2005.

FREITAS, Leda Gonçalves (org.). Prazer e sofrimento no trabalho docente: pesquisas brasileiras. Curitiba: Juruá, 2013.

GADOTTI, Moacir. Concepção dialética da educação: um estudo introdutório. 11. ed. São Paulo: Cortez, 2000.

GENTILI, Pablo. Desencanto e utopia: a educação no labirinto dos novos tempos. Petrópolis: Vozes, 2008.

GENTILI, Pablo; ALENCAR, Chico. Educar na esperança em tempos de desencanto. Petrópolis: Vozes, 2003.

GUÉRY, François; DELEULE, Didier. Le corps productif. Paris: Reéres-Mame, 1972. Mimeografado.

KUENZER, Acacia; CALDAS, Andrea. Trabalho docente: comprometimento e desistência. In: FIDALGO, Fernando; OLIVEIRA, Maria Auxiliadora; FIDALGO, Nara Luciene Rocha (org.). A intensificação do trabalho docente: tecnologias e produtividade. Campinas: Papirus, 2009.

MARX, Karl. O capital: crítica da economia política. Livro. 1. São Paulo: Boitempo, 2013.

MARX, Karl; ENGELS, Friedrich. Trabalho alienado. In: FERNANDES, Florestan (org.). Karl Marx e F. Engels: História. São Paulo: Ática, 1978.

OLIVEIRA, Dalila Andrade. A reestruturação do trabalho docente: precarização e flexibilização. Educação e Sociedade, Campinas, v. 25, n. 89, p. 1127-1144, set./dez. 2014. Disponível em: <https://bit.ly/2JzQQXm>. Acesso em: 20 nov. 2018.

RUBIN, Isaak Illiuch. A teoria marxista do valor. São Paulo: Polis, 1987.

SAVIANI, Dermeval. Educação, mudança, contestação, transformação. In: SAVIANI, Dermeval. Interlocuções pedagógicas: conversas com Paulo Freire e Adriano Nogueira e 30 entrevistas sobre educação. Campinas: Autores Associados, 2010. 
SAVIANI, Dermeval. História do tempo e o tempo da história: estudos de historiografia e história da educação. Campinas: Autores Associados, 2015.

SAVIANI, Dermeval. Trabalho e Educação: fundamentos ontológicos e históricos. In: REUNIÃO ANUAL DA ASSOCIAÇÃO NACIONAL DE PÓS-GRADUAÇÃO E PESQUISA EM EDUCAÇÃO, 29. 2006, Caxambu. Anais [...]. Caxambu: Anped, 2006. (GT - Trabalho e Educação).

SEVERINO, Antônio Joaquim. Educação, sujeito e história. São Paulo: Olho D’água, 2002.

SOTILI, Marines Rosa Palavicini. Entrevista Complementar. [Entrevista cedida a] Alcione Maria Bevilacqua. Quilombo, 24 abr. 2017. Manuscrito.

SILVA, Maurício Roberto da et al. Entre Esperanças e Utopias na Educação Básica: histórias de vidas e experiências docentes. 1. ed. Chapecó/SC: DR Publicidade, 2014.v.1.294 p.

SILVA, MAURíCIO Roberto da; DICKMANN, Ivo; BERNARTT, Maria de Lourdes. Radiografia do Golpe, neoliberalismo e destruição do Estado, "apagamento" dos direitos sociais, “Educação Temer(ária)”1 e Escola sem Partido. Revista Pedagógica, Chapecó, v. 19, n. 40, p. 7-21, jan./abr. 2017. ISSN: 1984-1566. DOI: http://dx.doi.org/10.22196/rp.v19i40.3759

VALMORBIDA, Itacir. A formação política dos docentes da rede pública de Ensino para além do capital: primeiras aproximações à luz de uma leitura materialista históricodialética. 2016. 213 f. Dissertação (Mestrado em Educação) - Universidade Comunitária da Região de Chapecó, Chapecó, 2016.

ZAMPIERON, Rosemari. Entrevista. In: SILVA, Maurício Roberto da et al. Entre Esperanças e Utopias na Educação Básica: histórias de vidas e experiências docentes. 1. ed. Chapecó SC: DR Publicidade, 2014. v. 1, p. 221-226. 